Special issue of the 3rd International Conference on Computational and Experimental Science and Engineering (ICCESEN 2016)

\title{
A Study of the Properties of Paper Sized with Styrene-Butyl Acrylate Copolymers
}

\author{
M. ÖZdemir ${ }^{a}$, M. ÖZdemir AlP ${ }^{b}$, A. AytaÇa, ${ }^{a, b}$ And V. Deniz ${ }^{a, b}$ \\ ${ }^{a}$ Polymer Science and Technology Department, Kocaeli University, Kocaeli, Turkey \\ ${ }^{b}$ Chemical Engineering Department, Kocaeli University, Kocaeli, Turkey
}

\begin{abstract}
In this study, styrene $70 \mathrm{wt} . \%$-butyl acrylate $30 \mathrm{wt} \%$ copolymer-based surface-sizing materials were synthesized using semi-batch emulsion polymerization and applied on the paper. Four different emulsifiers, with different ethylene oxide numbers, at ratios of $10 \%, 7 \%$ and (2,2'-azobis (2-methylpropionamidine) dihydrochloride (A)) as initiator were used for emulsion polymerization. Eight different copolymers were synthesized. Synthesized copolymers were used as surface sizing agents for the paper surface. Ion exchange capacity, pH, Fourier transform infrared spectroscopy, differential scanning calorimetry and thermal gravimetric analysis were used for the characterization of the copolymer properties. Contact angle measurements, Cobb test, and scanning electron microscopy analysis were carried out to determine the surface properties of the paper samples. Presence of copolymer formations was proven with the Fourier transform infrared analysis. Contact angle measurements of the copolymer sized paper surface have shown hydrophobic behaviour in samples, with the exception of E-3/7/A sample. The lowest Cobb value was observed for E-2/7/A sample. The highest thermal stability was also observed for E-2/7/A sample. The scanning electron micrographs show that the paper loses its fibrous structure and it is seen that the copolymer adheres to the fibrous tissue.
\end{abstract}

DOI: 10.12693/APhysPolA.132.1098

PACS/topics: 68.35.bm, 68.47.Mn, 81.05.Qk

\section{Introduction}

Cellulosic materials, such as paper, are usually hydrophilic. Its fibers have a strong tendency to water absorption. However, hydrophobicity is an essential property for many paper products, such as those used for writing, printing and packaging [1].

Surface sizing process is generally carried out during the manufacturing of paper, in order to reduce water absorption. The most commonly preferred sizing materials are rosin, starch, chitosan, polyvinyl alkol, carboxy methyl cellulose and styrene acylate emulsion [1-3].

The polymeric sizing agents are the members of this group of materials. Polymeric sizing has some advantages over the conventionally used sizing agents, such as high hydrophobicity and good stability [1]. For the present study styrene(St)-butyl acrylate (BA) copolymers were selected as the surface sizing agents. Emulsions of St-BA copolymers are widely used in paint, sizing and adhesive technology.

Many researchers and industries have been interested in the emulsion copolymerization of St with BA due to its practical significance [4]. Styrene and any type of acrylates commonly react by the method of emulsion polymerization. The kinetics of this reaction and the properties of emulsion were reported in several papers $[4,5]$. The reaction rate of the polymerization depends on the type and amount of emulsifier, initiator and also $\mathrm{pH}$ range of

*corresponding author; e-mail: aaytac@gmail.com the reaction mixture. Styrene-acrylate emulsion with an anionic, cationic or nonionic character can be produced, depending on the chemical structure of employed emulsifier [5].

In the literature, there are studies which investigated the influence of emulsifier type and content on the properties of St-BA copolymer latexes. Hua and Dube investigated the effects of five variables, i.e., St-BA ratio, methacrylic acid content, $\mathrm{pH}$, emulsifier content, and content of chain transfer agent on various product properties in the monomer-starved semi-batch emulsion copolymerization of St-BA [6]. They found that the latex particle size was mainly influenced by the emulsifier content and that $T_{g}$ values of the copolymers increased with St content in the monomer feed.

Zoco et al. studied the seeded emulsion copolymerization of St and BA in a weight ratio of 50/50. They analyzed the effect of process type (batch vs. semi-continuous) and the amounts of initiator and emulsifier loading, on the number of polymer particles, and average molecular weight. They observed that the average molecular weight depends, to a slight extent, on the emulsifier concentration and, to a greater extent, on the initiator concentration [7].

Wang and Fang performed another study in order to understand the effect of molecular structures of emulsifiers on the cationic emulsion co-polymerization of St and $\mathrm{BA}$, in details. Different types of emulsifiers were used in this study and they concluded that the cationic emulsion copolymerization of St-BA was greatly affected by the molecular structure of emulsifiers [8].

According to our knowledge, there are no studies in the literature, which deal with the effect of different 
ethoxylated amines containing emulsifiers on the St and BA emulsion polymerization. Also, there are no publications about the investigation of the surface properties of these copolymers as sizing materials.

In this study, styrene-acrylate-based copolymers were synthesized with emulsion polymerization by using styrene and butyl acrylate monomers. Four different ethoxylated amines (E1, E2, E3 and E4) were used as emulsifiers to investigate the effect of the emulsifier type and loading level on the performance of the surface sizing materials. For this purpose, contact angle measurements, Cobb test, ion exchange capacity, Fourier transform infrared spectroscopy (FTIR), differential scanning calorimetry (DSC), thermal gravimetric analysis (TGA) and scanning electron microscopy (SEM) analysis were performed.

\section{Experimental procedure}

\subsection{Materials}

In the experimental study; styrene and butyl acrylate were used as monomers. 2-2'-azobis (2-methylpropionamidine) dihydrochloride was used as an initiator and acetic acid was used for $\mathrm{pH}$ adjustment. Monomers for emulsion polymerization were provided from Soditaş (Turkey). The initiators, emulsifiers and acetic acid were obtained from Ak-Kim (Turkey).

\subsection{Synthesis of copolymers by emulsion polymerization}

St-BA copolymers were synthesized using the emulsion polymerization. In this polymerization system, four different ethoxylated amine type emulsifiers (E1, E2, E3 and E4) were used. There is a relationship based on the ethylene oxide $(\mathrm{EO})$ number, such that $\mathrm{E} 1<\mathrm{E} 2<\mathrm{E} 4<\mathrm{E} 3$. Emulsifiers were added by weight of the total amount of monomer system at $7 \mathrm{wt} . \%$ and $10 \mathrm{wt} . \%$ rates.

Content of initiator, 2,2'-Azobis(2-methylpropionamidine) dihydrochloride (A), and all other parameters were held constant. Eight copolymer samples were obtained in this manner. The copolymerization reactions were performed in a temperature controlled glass polymerization reactor system with nitrogen gas inlet and outlet.

For the production of copolymers by emulsion polymerization; the initiator, $1.0 \mathrm{wt} . \%$ of the total amount of monomer, was added into deionized water. The polymerization flask was purged of oxygen, during the reaction, by passing nitrogen gas. Pre-emulsion was prepared by using $70 \mathrm{wt} . \%$ styrene and $30 \mathrm{wt} . \%$ acrylate, water and emulsifier in another beaker.

The $\mathrm{pH}$ value was set to be in the range of 2 to 3 with acetic acid. When the polymerization temperature in the reactor reached $70^{\circ} \mathrm{C}$, pre-emulsion was added slowly to the reaction medium. After completing the addition of pre-emulsion, the reaction was carried out at a constant mixing speed of $750 \mathrm{rpm}$ for 4 hours. The synthesized copolymers were named by the type and amount of emulsifier and type of initiator. For example, the sample produced by using E-2 emulsifier, with amount of $10 \mathrm{wt} . \%$ and 2-2'-Azobis(2-methylpropionamidine) initiator was labeled as E-2/10/A.

\subsection{Sizing process}

Paper to be used for sizing process was produced using Estanit $(\mathrm{GmbH})$ paper machine. Produced paper was coated by using Mathis SVA-IR-B 605 sizing press and the synthesized copolymer. The equal amount of sizing solution was applied to the prepared paper. Sized paper was dried at $105^{\circ} \mathrm{C}$.

\subsection{Analysis of the copolymer samples}

FTIR analyzes were performed to determine the structure of copolymers. Each sample was analysed after drying in an oven at $105^{\circ} \mathrm{C}$ for 2 hours. ATR Thermo Scientific Nicolet FTIR instrument was used for analyses. DSC analysis was performed using Mettler Toledo Star System equipment DSC1. During thermal analysis of the copolymer sample, heating rate of $10^{\circ} \mathrm{C} / \mathrm{min}$ was applied. Analysis of all samples was carried out in -50 to $180^{\circ} \mathrm{C}$ temperature range.

Thermogravimetric analysis (TGA) was carried out with a Mettler TGA-1 instrument. Samples were heated from $30^{\circ} \mathrm{C}$ to $600{ }^{\circ} \mathrm{C}$ at a heating rate of $10^{\circ} \mathrm{C} / \mathrm{min}$ under $\mathrm{N}_{2}$ atmosphere. In order to determine ionic character of copolymer samples, a Mutec-PCD 03 particle charge detector was used.

Automatic titration was performed by using PES-Na solution and ionic consumption was recorded. Then the ion exchange capacity was calculated. Copolymer particle size (hydrodynamic radius) and polydispersity index (PDI) were measured using an ALV/CGS-3 compact goniometer system (Malvern, UK).

\subsection{Analysis of the sized paper}

Cobb test is a simple technique for measurement of water absorbency of paper. Cobb value, is defined as the mass of water absorbed in a specific time by one square meter of paper, board or corrugated fiber board, under $1 \mathrm{~cm}$ of water, in 60 seconds. Cobb measurements were made according to TAPPI standard T-441 of the Technological Association of the Pulp and Paper Industry.

The contact angle measurements were performed using the Theta Lite device. Distilled water was used in this measurement. Surface morphologies of the sized papers were examined by using JOEL JSM6335-F scanning electron microscope. Before the examinations, the surfaces of the papers were sputter coated with gold and palladium in order to prevent arcing.

\section{Results and discussion}

FTIR analysis was performed to determine the structure of the copolymer samples. Specific absorption peaks of copolymers containg $10 \mathrm{wt} . \%$ of emulsifier are given in Fig. 1. The bands at $3029 \mathrm{~cm}^{-1}$ can be assigned to the characteristic vibration peaks of phenyl ring. Deformation, and vibration peaks of the phenyl group in the St were observed at 1600 and $695 \mathrm{~cm}^{-1}$. These peaks were clearly explained by the formation of copolymer [9]. 


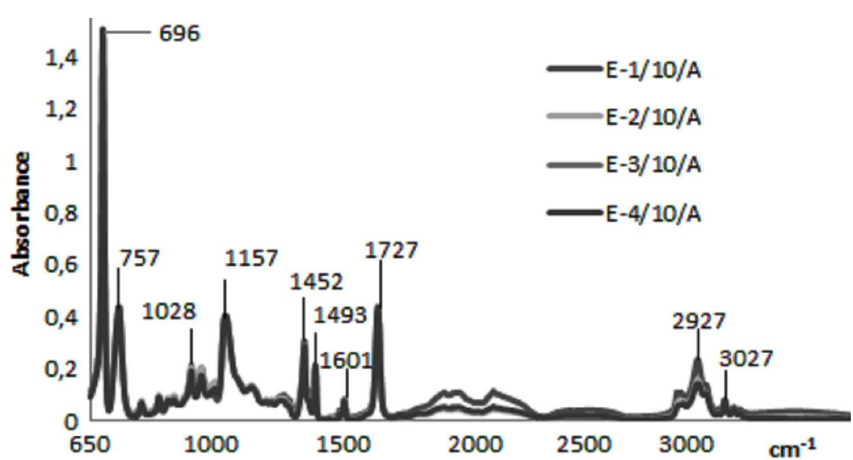

Fig. 1. FTIR spectra of copolymers containg 10 wt.\% of emulsifier.

Besides, all of the typical bends due to St, which are located at approximately 1600, 750 and $700 \mathrm{~cm}^{-1}$ and the peak at $1729 \mathrm{~cm}^{-1}$ correspond to the $\mathrm{C}=\mathrm{O}$ group of BA [6].

Characteristic properties of the synthesized copolymers are given in Table I. Glass transition temperatures $T_{g}$ of the copolymers were determined using DSC. As we know, $T_{g}$ values of poly (butyl acrylate) and polystyrene are $-52^{\circ} \mathrm{C}$ and $100{ }^{\circ} \mathrm{C}$ respectively [9]. It was found that the $T_{g}$ values for the synthesized copolymers were situated between these two values. The glass transition temperatures of copolymers were observed between $40^{\circ} \mathrm{C}$ and $51^{\circ} \mathrm{C}$. The highest $T_{g}$ value was found for $\mathrm{E} 3 / 7 / \mathrm{A}$ copolymer sample. This copolymer was synthesized by using E3 emulsifier which has the highest EO number. In addition to this, the $T_{g}$ values decrease with the increasing levels of emulsifier loading, because of the soft part on the EO number of emulsion molecular chain.

TABLE I

Characteristic properties of synthesized copolymers.

\begin{tabular}{c|c|c|c|c|c|c|c|c}
\hline \hline & $\mathrm{E}-1 / 10 / \mathrm{A}$ & $\mathrm{E}-1 / 7 / \mathrm{A}$ & $\mathrm{E}-2 / 10 / \mathrm{A}$ & $\mathrm{E}-2 / 7 / \mathrm{A}$ & $\mathrm{E}-3 / 10 / \mathrm{A}$ & $\mathrm{E}-3 / 7 / \mathrm{A}$ & $\mathrm{E}-4 / 10 / \mathrm{A}$ & $\mathrm{E}-4 / 7 / \mathrm{A}$ \\
\hline $\mathrm{pH}$ & 3.9 & 3.8 & 3.8 & 4.1 & 3.8 & 3.9 & 3.6 & 3.3 \\
Solid content [\%] & 38.5 & 44.4 & 37.2 & 35.0 & 40.2 & 41.2 & 38.4 & 45.6 \\
Ion exchange capacity [meq/gr] & 0.34 & 0.20 & 0.20 & 0.15 & 0.11 & 0.11 & 0.13 & 0.12 \\
$T_{g}\left[{ }^{\circ} \mathrm{C}\right]$ & 40 & 41 & 40 & 43 & 44 & 51 & 44 & 47 \\
Radius [nm] & 36.9 & 40.5 & 30.9 & 45.0 & 32.8 & 33.8 & 30.7 & 34.9 \\
PDI & 0.09 & 0.07 & 0.05 & 0.05 & 0.11 & 0.10 & 0.09 & 0.05
\end{tabular}

The radii values of copolymers in the emulsion, versus type of emulsifiers and loading level are given in Table I. The results show that the average molecular diameters of particles are in the range of 30.7-45.0 nm. Solid contents, $\mathrm{pH}$ values and ionic properties of synthesized copolymers were also measured.

The solid contents of copolymers varied between 35.0 and 45.6 wt.\%. It was determined that the $\mathrm{pH}$ values varied from 3.3 to 4.1. According to the ion exchange capacity analysis, copolymers of cationic type were obtained in all copolymer samples. The highest ion exchange capacity was obtained in E-1/10/A sample.

TGA analysis was performed to define the thermal stability of the synthesized copolymers. A two-stage decomposition was observed. Firstly, water content of the copolymer was lost and then, in the second stage, the degradation of the copolymers occurred.

The solid content of copolymers can be estimated from TGA curves given in Fig. 2. It was found that the highest thermal stability was observed for E-2/7/A sample. The temperature of the extraction of water from the latex changed between $104^{\circ} \mathrm{C}$ and $123^{\circ} \mathrm{C}$, while the decomposition temperature of the copolymer ranged from $403^{\circ} \mathrm{C}$ to $411^{\circ} \mathrm{C}$.

Contact angle and Cobb values of the copolymer samples are given in Table II. The contact angle values of

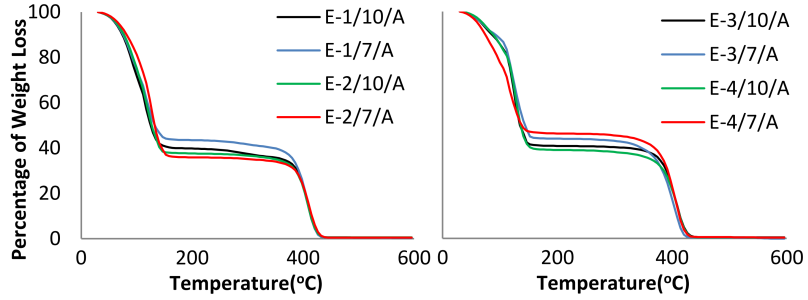

Fig. 2. TGA curves of the copolymers.

all samples were greater than $90^{\circ}$, except for E-3/7/A Materials with contact angles above $90^{\circ}$ are called hydrophobic in the literature.

It is known that water resistance of paper is decreased with the increase of Cobb values. In this study, the lowest Cobb values were obtained in the $\mathrm{E}-2 / 7 / \mathrm{A}$ copolymer sample. Cobb value of untreated paper was measured as $254 \mathrm{~g} / \mathrm{m}^{2}$. Cobb measurements have shown that water resistance of sized paper was improved by $65 \%$, compared to the untreated sample.

The surface morphology of the sized and untreated paper was investigated by SEM. The SEM micrographs are given in Figs. 3 and 4 . A fibrous structure was clearly seen on the surface of the untreated paper (Fig. 3). On 
TABLE II

Cobb value and contact angles of the sized paper samples.

\begin{tabular}{c|c|c}
\hline \hline & Contact angle $\left[{ }^{\circ}\right]$ & Cobb $\left[\mathrm{g} / \mathrm{m}^{2}\right]$ \\
\hline $\mathrm{E}-1 / 10 / \mathrm{A}$ & 102.51 & 91 \\
$\mathrm{E}-1 / 7 / \mathrm{A}$ & 91.63 & 109 \\
$\mathrm{E}-2 / 10 / \mathrm{A}$ & 97.92 & 81 \\
$\mathrm{E}-2 / 7 / \mathrm{A}$ & 96.28 & 76 \\
$\mathrm{E}-3 / 10 / \mathrm{A}$ & 102.95 & 93 \\
$\mathrm{E}-3 / 7 / \mathrm{A}$ & 80.83 & 88 \\
$\mathrm{E}-4 / 10 / \mathrm{A}$ & 91.96 & 92 \\
$\mathrm{E}-4 / 7 / \mathrm{A}$ & 99.86 & 100
\end{tabular}

the other hand, some of the sized paper samples have lost the fibrous structure, especially the sample with 7 wt.\% of emulsifier. It was found that the leaking of the emulsion between the fibrous structures of the paper is due to the increasing emulsifier content and EO number.

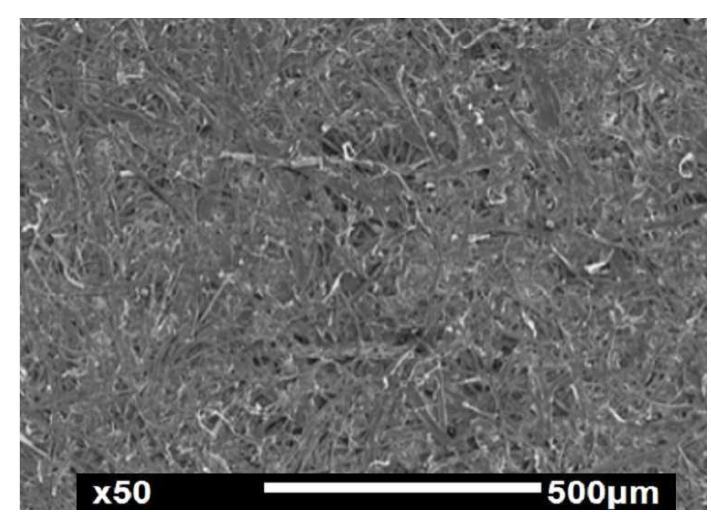

Fig. 3. 50× SEM micrographs of the surface of untreated paper.

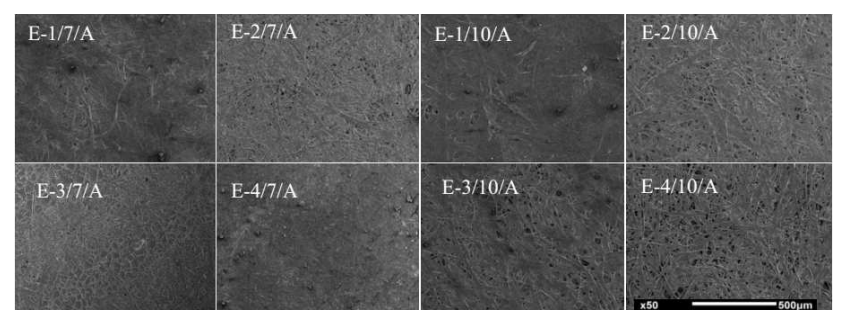

Fig. 4. 50× SEM micrographs of the surface of sized paper.

\section{Conclusions}

In this study, the effects of emulsifier type and loading level on the emulsion polymerization were investigated. Copolymers of cationic type were obtained in all cases. The glass transition temperatures of copolymers, measured by DSC, were found to be between 40 and $51^{\circ} \mathrm{C}$. The particles of copolymers in emulsion were almost monodisperse and had average molecular diameter between 30.7 and $45 \mathrm{~nm}$. The formation of copolymers was verified by FTIR measurements. The highest ion exchange capacity was obtained in sample E-1/10/A. According to the SEM analysis, the uniform distribution was observed in E-2/7/A sample. The lowest Cobb values were obtained in $\mathrm{E}-2 / 7 / \mathrm{A}$ copolymer sample.

\section{Acknowledgments}

This study was supported by Ministry of Science, Industry and Technology of Turkey under the Project number 0011.STZ.2013-1.

\section{References}

[1] N. Yang, Y. Deng, J. Appl. Polym. Sci. 77, 2067 (2000).

[2] G. Yu-Hua, L. Shu-Cai, W. Gao-Sheng, M. Weib, H. Zhen, Progr. Organic Coat. 74, 248 (2012).

[3] J. Xu, H. Hu, J. Appl. Polym. Sci. 123, 611 (2012).

[4] V. Chrŕstovŕ, S. Ďuračkovŕ, J. Mrenica, L. Černŕkovŕ, Chem. Papers 53, 140 (1999).

[5] A.M. Santos, F.M.B. Coutinho, Polym. Bull. 30, 407 (1993).

[6] H. Hua, M.A. Dubé, Polym.-Plast. Technol. Engin. 50, 349 (2011).

[7] N. Zoco, L. Lopez de Arbina, J.R. Leiza, J.M. Asua, G. Arzamendi, J. Appl. Polym. Sci. 87, 1918 (2003).

[8] Fei Wang, Kuan Jun Fang, Coll. Polym. Sci. 292, 1449 (2014).

[9] Wenwen Wang, Qiuyu Zhang, Feige Guo, Junwei Gu, Changjie Yin, J. Polym. Res. 18, 1229 (2011). 